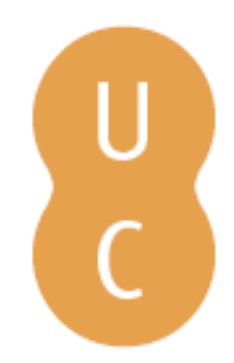

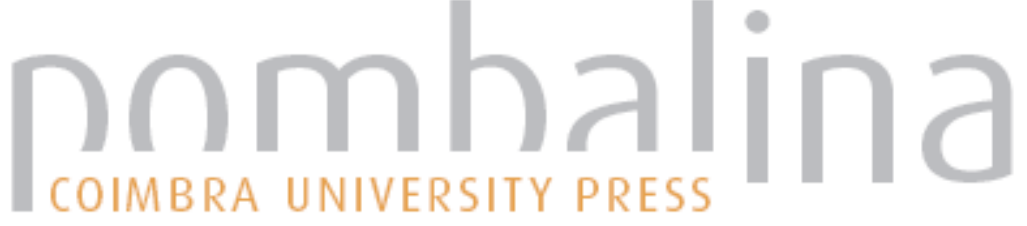

\section{O Mediterrâneo nos roteiros medievais}
Autor(es):
Espírito Santo, Arnaldo do
Publicado por: Imprensa da Universidade de Coimbra
URL persistente:
URI:http://hdl.handle.net/10316.2/38357
DOI:
DOI:http://dx.doi.org/10.14195/978-989-26-0438-1_18
Accessed : $\quad$ 26-Apr-2023 11:45:53

A navegação consulta e descarregamento dos títulos inseridos nas Bibliotecas Digitais UC Digitalis, UC Pombalina e UC Impactum, pressupõem a aceitação plena e sem reservas dos Termos e Condições de Uso destas Bibliotecas Digitais, disponíveis em https://digitalis.uc.pt/pt-pt/termos.

Conforme exposto nos referidos Termos e Condições de Uso, o descarregamento de títulos de acesso restrito requer uma licença válida de autorização devendo o utilizador aceder ao(s) documento(s) a partir de um endereço de IP da instituição detentora da supramencionada licença.

Ao utilizador é apenas permitido o descarregamento para uso pessoal, pelo que o emprego do(s) título(s) descarregado(s) para outro fim, designadamente comercial, carece de autorização do respetivo autor ou editor da obra.

Na medida em que todas as obras da UC Digitalis se encontram protegidas pelo Código do Direito de Autor e Direitos Conexos e demais legislação aplicável, toda a cópia, parcial ou total, deste documento, nos casos em que é legalmente admitida, deverá conter ou fazer-se acompanhar por este aviso.

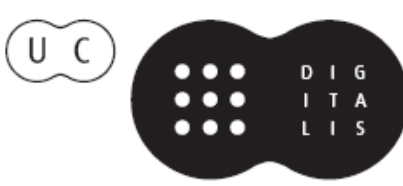


Francisco de Oliveira

Pascal Thiercy

Raquel Vilaça

Coordenação

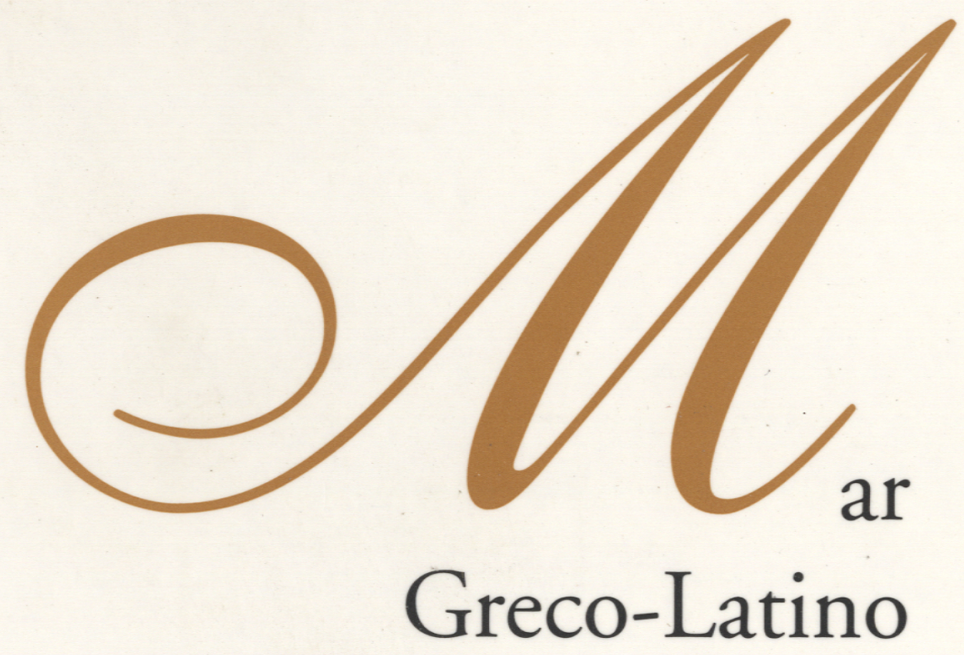

- colmbra 2006 


\title{
O MEDITERRÂNEO NOS ROTEIROS MEDIEVAIS
}

\author{
Arnaldo do Espírito Santo \\ Faculdade de Letras de Lisboa
}

No latim clássico, o adjectivo mediterraneus é antónimo de maritimus e qualifica uma região que se situa longe do mar, uma cidade ou uma povoação do interior. Tito Lívio refere que, durante as campanhas da Ásia Menor, o exército romano chegou a Górdio, que é um «haud magnum oppidum (...) sed plus quam mediterraneum celebre et frequens emporium» ${ }^{(1)}$, ou seja, que é um empório mais populoso e frequentado do que seria de esperar de uma pequena cidade do interior: o adjectivo utilizado é mediterraneum. Górdio, mediterraneum emporium, era de facto uma cidade, bem do interior, situada nos confins da Frígia e da Galácia, entre montanhas. É neste sentido que mediterraneum, como substantivo, é usado por Plínio, quando escreve que Cremona e Bréscia ficam situadas «in mediterraneo» ${ }^{(2)}$. A designação usada por Plínio para se referir ao Mediterâneo é «internum mare»(3).

Mediterrâneo, com o sentido actual, surge no latim pós-clássico. Mas é ainda no sentido clássico que S. Jerónimo escreve que um certo homem,

\footnotetext{
(1) Ab Vrbe condita, 38, 18, 11ss.

(2) N. H. (=Naturalis Historia), 3, 130.

${ }^{(3)}$ N. H. 3, 4; 3, 31; 5, 18.
} 
curado por milagre, se afastou «ad mediterranea loca, id est, vicesimo a mari milliario» (para trinta quilómetros do mar), a fim de não ser importunado pelos curiosos, vindos do Oriente. Hilário de Poitiers (séc. IV), na esteira de Plínio, designa o Mar Mediterrâneo por «internum mare» ${ }^{(4)}$. A denominação Mediterraneum mare ou mare Mediterraneum está documentada pela primeira vez em Isidoro de Sevilha(5) (séc. VII) e divulgou-se nos escritores medievais a partir da época carolíngia, vindo substituir a designação internum mare $^{(6)}$. Assim, mediterraneum, como substantivo, passa a identificar o internum mare, bem como o conjunto de terras que o circundam e ainda estas mesmas terras. Do ponto de vista geográfico, um texto do séc. III considera o mediterraneum uma região situada entre o Oriente e o Ocidente. Refiro-me a um Chronicon, da autoria de um anónimo que, tomando por referência o livro do Génesis, diz que Noé, após o Dilúvio, distribuiu a terra pelos seus filhos: «Et quidem Sem primogenitus accepit Orientem; Cham autem Mediterraneum; Jafet Occidentem» ${ }^{(7)}$. E por mais ingénua que pareça esta divisão do mundo pelos filhos de Noé - o Oriente para Sem, o primogénito, o mais antigo; o Ocidente para Jafet; o Mediterrâneo, a terra entre as terras, a região do meio, para Cam - por mais ingénua que seja esta distribuição, ela encerra um conceito antropológico e geopolítico, pois o mediterrâneo é sentido como um espaço culturalmente bem definido, que se organiza, como diz Bowersock ${ }^{(8)}$, em torno de um mar interior, com um modo de viver em sociedade segundo leis, e instituições políticas e administrativas, com um sentido de bem comum, com princípios de uma moral individual e colectiva baseada na justiça.

\footnotetext{
(4) Tractatus super psalmos, PL (= Patrologia Latina), 9: 417: "Quin etiam interni atque externi maris insulae in huius nominis uirtute requiescunt.,

(5) Etymologiae, PL 82: 484, 496, 504

(6) Veja-se, a título de exemplo, Rabano Mauro, De universo ( $P L$ 111: 312, 335).

(7) Chronicon anonymi, PL 3, 666.

(8) Cf. G. W. Bowersock et alii, Late Antiquity. A Guide to the Posclassical World, Cambridge, Massachusetts, and London, $2000^{2}$, pp. 572-573.
} 
Outros sentidos se desenvolveram para Mediterraneum. Para um autor do séc. XI, como é Herman de Reichnau, o Mediterrâneo é uma área climática ${ }^{(9)}$. O Papa Urbano II (1088-1099) considera o Mediterrâneo um espaço estratégico que é necessário proteger a todo o custo, até à violência, se os cristãos querem ter paz e salvaguardar os direitos da Igreja. Foi contra o perigo da invasão total desse espaço, que lançou o apelo à primeira cruzada em 1094. O seu maior argumento é que, com a invasão dos Turcos e dos Árabes, está em perigo a religião cristã, que é parte essencial da cultura mediterrânea. Como argumento apelativo, em linguagem violenta e crua, salienta que o perigo da guerra é iminente, que as igrejas estão a ser arrasadas, os cristãos trucidados ou feitos prisioneiros.

Esta proclamação do Papa foi retomada com os mesmos tópicos pelos autores que escreveram sobre a gesta da primeira cruzada e dos anos de conquista e resistência que se lhe seguiram. Um deles foi Fulcher de Chartres (1059-1127), um dos cruzados, que na sua Historia Hierosolymitana, cita textualmente Urbano II, e entre outros argumentos invocados diz que aloca sancta uiolari, monasteria uillasque igni cremari, nulli mortalium parci, diuina et humana ludibriis haberi» ${ }^{(10)}$. A ideia de uma civilização que se desenvolveu em torno do Mare Mediterraneum, está patente nos tratados de geografia que, na linha de Pompónio Mela, o tomam como ponto de referência para a descrição dos países e cidades, para o curso dos rios e localização das montanhas. Assim, é dito que anter Euphratem et mare Mediterraneum sunt Syria, Phoenicia et Palaestina, quae continet Iudaeam, Samariam et Galilaeam. ${ }^{(11)}$ »Estes países estão integrados num espaço que lhes é conatural, não apenas fisicamente, mas também por religião, cultura e história comuns. E o autor anónimo prossegue: «Inter Danubium et mare Mediterraneum sub Euxino et Hellesponto sunt Mesia, Histria, Macedonia, et sub Macedonia ab

\footnotetext{
(9) De utilitatibus astrolabii, PL 143: 404.

${ }^{(10)}$ Historia Hierosolymitana, PL 155: 827.

${ }^{(11)}$ Auctor incertus, Excerptiones Allegoricae, PL 177: 209.
} 
aquilone ad austrum, Arcadia, Hellada, Thessalia, Achaia. (...) inter Alpes et mare Mediterraneum, sunt Campania, Apulia, Tuscia, Calabria, Liguria, Italia quae et Latium, Umbria. ${ }^{(12) \text {, }}$

Serve esta introdução para enquadrar os textos, que a seguir se analisam, num conceito de Mediterrâneo, enquanto mar e terra do interior, assente numa cultura e modo de viver comuns, com raízes na livre comunicação entre várias comunidades congregadas sob o Império Romano, herdeiro do humanismo clássico e dos valores bíblicos. A base desta comunicação está numa reflexão conduzida sobre a leitura dos textos dos itinerários seguidos pelos ocidentais a caminho do Oriente para as fontes da cristandade, logo a partir do séc. IV, para culminar, já no limite dos séculos XI/XII, nas viagens feitas pelos cruzados e peregrinos, por terra e por mar.

O primeiro itinerário que se conhece, de autor desconhecido, é uma viagem à Terra Santa empreendida em meados do século IV, na sequência do anúncio da descoberta em 335 da Cruz de Cristo e da construção das duas basílicas constantinianas, uma no Calvário, outra no Santo Sepulcro(13). O autor deste Itinerarium é um peregrino que parte de Bordéus pela estrada romana que corre de oeste para sudeste pelo vale do Garona até Toulouse, seguindo depois para leste por Carcassonne e Narbonne; a partir daí inflecte para nordeste seguindo a linha da costa por Béziers (ciuitas Biterris), Nîmes (ciuitas Nemauso) e Arles (ciuitas Arelatae). De Bordéus a Arles estão contabilizadas 371 milhas, o que faz cerca de $550 \mathrm{Km}$, feitos em 40 etapas, o que significa 40 dias de viagem, com quarenta mudas de diligência.

A partir de Arles vai para nordeste pela estrada de Avignon (ciuitas Avenione), Orange (ciuitas Arausione), Valence (ciuitas Valentina). Passa os Alpes e entra em Itália em direcção a Turim, seguindo depois para Milão

\footnotetext{
(12) Idem, PL 177: 212.

(13) Anonymi itinerarium a Burdigala Hierusalem usque, et ab Heraclea per aulonam et per urbem Romam Mediolanum usque, PL 8: 783.
} 
(ciuitas Mediolanum). Feito o balanço, de Arles a Milão são mais 425 milhas (uns $630 \mathrm{Km}$ ) e 22 dias de viagem. Inexplicavelmente a velocidade de deslocação foi o dobro da de Bordéus a Arles. Seja qual for a explicação, a viagem vai já em dois meses.

De Milão vai por Bréscia, Benevento, Verona, Vincenza, Pádua e chega a Aquileia, percorridas já 251 milhas $(372 \mathrm{Km})$. A viagem já leva 2 meses e 11 dias.

A rede viária e a toponímia urbana continuam a ser as que nos aparecem nos textos clássicos. O nosso peregrino, quando esperaríamos que tomasse um barco, prosseguindo a viagem por mar, avança pela Panónia inferior até Sírmio, integrado num sistema de transportes terrestres que funciona com regularidade. De Aquileia até Sírmio foram mais $630 \mathrm{Km}$ percorridos em 17 dias. E já lá vão três meses de viagem.

De Sírmio até Sérdica, nos confins da Dácia, são 314 milhas (466 Km) em 13 etapas. Depois de percorrer, desde Sérdica, mais 413 milhas (613 Km), chega ao fim de 20 dias a Constantinopla, 3 meses e 3 semanas após a partida de Bordéus. Estava-se em finais de Maio. Era cônsul Zenófilo. O que significa que a partida de Bordéus tinha sido em princípios de Fevereiro.

A viagem prossegue com a travessia do Ponto, isto é, do Bósforo, para Calcedónia. É a primeira vez que em toda a viagem se faz caminho pelo mar. E mais uma vez, supondo que entre Constantinopla, capital do Império do Oriente, e a Palestina havia ligações marítimas regulares, a viagem continua por terra através da Bitínia (Norte da Ásia Menor), com uma paragem em Libissa, onde se diz que está sepultado o «Rex Annibalianus, qui fuit Afrorum», isto é, Aníbal o Cartaginês. É a primeira nota turística de interesse cultural, que aliás revela um conhecimento muito vago da história, mas que pressupõe uma visita ao túmulo de Aníbal. Ao fim de 8 milhas contadas desde Constantinopla chega-se a Nicomédia em 3 etapas, provavelmente com uma visita a Calcedónia. 
A viagem prossegue por Niceia e daí para Ancira, a leste, no interior, através da Galácia. São doze dias para 383 Km, 258 milhas. Assinala-se a cidade de Tiana, em plena Capadócia, terra natural de Apolónio, pregador e taumaturgo. Chega depois à Cilícia, onde fica a cidade de Tarso, primeira referência de turismo religioso, a propósito de S. Paulo. Depois: Antioquia, Síria, Fenícia, Trípoli, Sídon, onde Elias se hospedou em casa da Viúva de Serepta, Tiro.

A partir daqui acumulam-se as referências de interesse para o turismo religioso, que é sem dúvida o motivo final por que foi redigido este itinerário: assinala-se o Monte Carmelo relacionado com Elias. Chega-se a Cesareia da Palestina ( «id est, Iudaea»).

O ponto de vista do Itinerarium Burdigalense é o de um peregrino, um clérigo, ou talvez um mercador que vai à Terra Santa «cum eruditionis, tum etiam religionis causa», para usar uma expressão de S. Jerónimo. Tem por guia a Bíblia que leva na memória; nos lugares aonde chega, encontra por parte dos agentes locais (mosteiros, igrejas, pequenas comunidades) guias que lhe mostram os pontos de interesse: em Cesareia de Filipe visita os banhos ditos do Centurião Cornélio, baptizado por S. Pedro como consta do cap. X dos Actos dos Apóstolos. Em Cesareia deixa o caminho do mar e segue para o interior, passando por Siquém, pelo poço de Jacob, recordando o episódio da Samaritana. Ao todo, de Cesareia da Palestina até Jerusalém foram 116 milhas, cerca de $170 \mathrm{Km}$, percorridos em 4 etapas. A quem chega a Jerusalém deparam-se-lhe os grandes monumentos dos tempos bíblicos, sumariamente descritos. Em Jerusalém e ao redor são visitados os lugares associados a Cristo e aos Apóstolos. Há uma visita a Jericó, a Betânia, ao Jordão, ao mar morto, a Belém, etc. Volta-se a Jerusalém, para retomar a viagem do regresso, descrita em alternativa sumariamente. Só um pormenor, é que em Dezembro o peregrino estava em Constantinopla de regresso aparentemente pelo mesmo percurso. Mas apesar disso apresenta uma alternativa de regresso, tomando o barco em Cesareia, como fez S. Paulo. Outra hipótese é partir de Heracleia através da Macedónia. A passagem por Filipos é assinalada com a evocação 
da prisão de S. Paulo, de que se fala nos Actos dos Apóstolos ${ }^{(14)}$. São enumeradas as cidades de Apolónia, Tessalonica, Péla, todas na Macedónia, e, já no Epiro, Aulona. Faz-se a travessia de barco para Brindisi, sobe-se pela Apúlia e pela Campânia: Benevento, Cápua, Terracina até Roma, por terra, em nove etapas, com 14 mudas. De Roma vai-se a Milão e termina o Itinerarium, fechando-se o círculo.

Feito o resumo deste périplo que teria durado cerca de um ano, permitam-me algumas considerações. O Itinerarium Burdigalense dá-nos a imagem do Mediterrâneo das comunicações entre as várias cidades e regiões longínquas, com estruturas de circulação de pessoas por terra e por mar; com transportes, que têm pontos fixos (as mutationes) para mudança de equipagem, e estalagens (mansiones) para pernoita. A imagem dada do Mediterrâneo do séc. IV, entendido aqui não apenas como mar, é a de um espaço de liberdade, de unidade política, de forma de viver, de circulação de bens, de mercadoria e de cultura; é, enfim, a imagem de um espaço de segurança criado pelo Império Romano. Em toda a viagem não há uma só referência que seja a ataques de salteadores por terra ou de piratas no mar.

Entretanto, verificamos que algo mudou radicalmente quando passamos à leitura do chamado Itinerário de Antonino, obra de vários autores de épocas distintas, provavelmente do séc. VI, com aproveitamento de elementos de época anterior e acrescentos posteriores, atribuído a Santo Antonino Mártir, soldado sob o imperador Diocleciano (séc. III/IV), mas que contém referências a Justiniano (séc. VI). O pretenso mártir vai em peregrinação à Terra Santa, para, seguindo os passos de Cristo; aver os milagres dos santos profetas» (amiracula sanctorum prophetarum peruidere») ${ }^{(15)}$.

Embora o pseudo-Antonino Mártir parta de Piacenza, no Norte de Itália, a viagem inicia-se apenas a partir de Constantinopla. Primeira questão: até

(14) 16,22 ss.

(15) Antonini Placentini itinerarium, PL 72: 899 
Constantinopla, fez-se a viagem por terra, seguindo o itinerário do correio imperial, como no Itinerarium Burdigalense? Seria possível.

Saindo de Constantinopla, por mar, em direcção a Chipre, sem ter noção das centenas de quilómetros que era necessário percorrer, descreve-se a cidade cipriota de Constância onde repousa Santo Epifânio (Bispo no tempo de S. Jerónimo), passando-se de imediato à Síria e fundeando no porto da cidade de Tiro. O percurso que se segue daí para sul leva-nos à Galileia, com as esperadas visitas a Nazaré, Caná; e, de uma forma pouco lógica, vai-se a Trípoli e a Beirute (para norte), que se diz ser um antigo e famoso centro de estudo das letras, o que só pode ser verdade no século XI. A visita decorre sem qualquer plano racional, facto que pode indiciar que se trata de um Itinerarium de ficção, escrito por quem não conhece a geografia das regiões que vai descrevendo. Um pormenor interessante e que se encontra no Itinerarium de Egéria, de finais do século IV, é que se faz uma deslocação ao Monte Sinai e ao Monte Horeb, onde vive uma multidão de monges. O mesmo que fora dito do vale do Jordão. A viagem prossegue com a travessia do Mar Vermelho para o Egipto num barco mercante que vinha da Índia. E de novo a visita aos monges do deserto e às cataratas do Nilo.

Depois de uma visita a Alexandria, volta-se a Jerusalém para o regresso. E assim, depois de muitas voltas, os peregrinos cansados da viagem, tão longa, voltam por mar para Itália e com júbilo chegam a Piacenza, «a nossa cidade, situada nas margens do rio Pó»(16).

Verdadeiramente, o que o Itinerarium de Antonino transmite é a ideia de uma explosão da vida monástica pela Terra Santa, pela região do Sinai e pelos desertos do Egipto, anterior à ocupação muçulmana do séc. VII. E qualquer que seja o seu valor documental serve-nos de ponto de confronto

\footnotetext{
(16) Idem, PL 72: 918: «ovantes, venimus Placentiam civitatem nostram, positam super fluvium qui dicitur Padus, infra iam dictam Italiam.
} 
com um outro Itinerarium factum in loca sancta anno 870, da autoria de Fr. Bernardo, um monge bretão da abadia de Mont-Saint-Michel ${ }^{(17)}$.

A história que nos conta é a de três monges, um francês, um italiano e um hispânico, que se associam para fazer uma peregrinação à Terra Santa. Um elemento novo é que se dirigem a Roma para pedir autorização ao Papa Nicolau I (858-867). Estamos em Idade Média profunda. Os Muçulmanos tinham invadido a Hispânia havia mais de 150 anos. Entre 840 e 871 as tropas muçulmanas conquistam Bari e devastam a Itália. Mas, apesar disso, e ao contrário dos roteiros anteriores, o Itinerário de Bernardo conduz os três monges peregrinos à cidade de Bari. Em primeiro lugar, facto verdadeiramente novo no Mediterrâneo desde os tempos dos Romanos, dirigem-se ao emir local para pedir um salvo-conduto para apresentar ao de Alexandria, no Egipto. Um e outro estão na dependência do Sultão de Bagdad que fica para lá de Jerusalém.

Obtido o salvo-conduto, seguem para o porto de Tarento, onde se encontravam seis navios com nove mil cativos cristãos de Benevento. Este é o segundo facto novo que assinala mudanças essenciais no Mar Mediterrâneo, que de mar livre se tornara cativo e veículo do comércio de escravatura em grande escala. Percebe-se que dos seis navios dois iam para a região de Cartago, levando três mil escravos; dois tinham como destino o porto de Trípoli, na Líbia, e levavam mais três mil escravos; os outros dois transportavam três mil escravos para Alexandria no Egipto. Outro facto novo, é que ao contrário do que sucedia nos séculos anteriores, em que os percursos se faziam por terra, curiosamente no tempo em que era livre e segura a navegação no mar Mediterrâneo, agora a viagem para a Palestina é feita por mar via Egipto, numa época em que a mesma navegação estava sob apertado controlo das potências muçulmanas. Uma quarta ilação a tirar é que o porto de Tarento era uma espécie de entreposto que ligava o mundo ocidental

(17) Bernardi itinerarium factum in loca sancta anno DCCCLXX, PL 121: 569. 
muçulmano ao mundo oriental, se não com três carreiras regulares, pelo menos com três destinos previstos: Cartago, Líbia, Egipto. Havia uma estrutura 356 montada, de características comerciais, por certo, e, se não servia apenas para transportar cativos, o que é impensável, podemos ver nelas uma forma organizada de comunicações regulares. Não é de crer todavia, neste século IX, que se mantivesse um comércio intenso e activo, entre o mundo muçulmano e o mundo ocidental cristão, através do Mar Mediterrâneo. Vislumbramos, pelo contrário, grandes entraves à livre circulação de pessoas e mercadorias.

Os três peregrinos chegam a Alexandria ao cabo de trinta dias de navegação. Não era muito, comparando com os três meses e três semanas que o peregrino de Bordéus tinha levado a chegar a Constantinopla. Mas, ao contrário do que vemos suceder aos peregrinos do Itinerarium de Antonino, que se passearam livremente pelo Sinai, pelo deserto e por Alexandria, os três peregrinos, logo que aportam a esta mesma cidade, indo a sair do navio são impedidos pelo comandante. A autorização para sair custou-lhes seis áureos, dois por cada um.

Dirigiram-se então ao emirato de Alexandria com o salvo-conduto concedido pelo emir de Bari. De nada serviu. Ele reconheceu o documento, mas tiveram de pagar mais doze denários cada um. Em troca foi-lhes concedido novo salvo-conduto para ser apresentado ao emir de Babilónia. Babilónia era o nome que então se dava à cidade do Cairo.

O que doravante divide o espaço do Mediterrâneo são duas culturas que se defrontam e não sei se duas religiões. Na verdade, chegados a Alexandria, os três peregrinos encontram testemunhos de que, segundo a tradição, aí S. Marcos pregou o Evangelho. Fora de portas, a oriente, há um mosteiro da invocação do Evangelista, no qual há monges. Lá está uma igreja onde primeiramente esteve sepultado, antes de os Venezianos terem levado o seu corpo às escondidas para a sua ilha, isto é, para Veneza. Ao sair da porta ocidental, há outro mosteiro em que vivem monges. Em suma, para território 
dominado pelos Muçulmanos desde 642 (havia mais de dois séculos) o cristianismo mantinha-se bastante vivo e florescente, em liberdade.

Pela porta sul entra um braço do Nilo que atravessa a cidade. Os peregrinos viajam para sul, pelo Nilo, durante seis dias até à cidade de Babilónia, «onde reinou o Faraó». Aqui, novo controlo dos salvos-condutos por parte das autoridades. Apesar de serem mostrados os documentos passados em Alexandria, nada evitou que fossem encarcerados durante seis dias, até ser decidido que pagariam treze denários cada um. O controlo de estrangeiros era rigoroso. Em qualquer cidade em que entravam, não os deixavam sair antes de receberem um salvo-conduto ou um carimbo no que tinham, o que custava um ou dois denários. História miúda, mas que é bem elucidativa de quanto a circulação de pessoas era dificultada, com todas as consequências daí advenientes, que se repercutiam na desagregação de um espaço mediterrâneo comum e no fechamento das comunidades sobre si mesmas, na incompreensão mútua e no atrofiamento das relações comerciais.

No entanto, deve reconhecer-se que a civilização do Islão, ao fim de dois séculos de dominação, se mantinha tolerante. No Cairo, a estrutura eclesiástica não tinha sofrido abalos; o Patriarca Miguel superintendia sobre todos os bispos, monges e cristãos. Os três peregrinos reparam, todavia, que os cristãos pagavam um tributo anual «pro posse personae suae», segundo as suas posses, "para poderem viver em segurança e liberdade» ${ }^{(18)}$. Este tributo ou imposto, não ia além de três áureos e, no caso dos menos favorecidos, fica pelos treze denários. O mais grave é que quem não pagar, seja ele nativo ou estrangeiro, é metido na prisão até que seja redimido por outros cristãos.

Depois da visita ao Cairo, os três peregrinos descem o Nilo, passam pela cidade de Mahalla e chegam a Damieta. Mais uma observação: ali perto fica Tánis, an qua sunt Christiani multi, aut enim religiosi hospitalitate nimia fer-

(18) Idem, PL 121: 571B. 
ventes ${ }^{(19)}$. Em síntese: apesar da mudança radical ocorrida com a expansão muçulmana, o Mediterraneum continuava a contar, em ambas as margens, com uma florescente implantação cristã. E por isso este roteiro não pode deixar de reparar nas Igrejas de Tánis e especialmente, em Faramea, na igreja de Santa Maria, no local para onde ela fugiu com S. José e o Menino. O que quer dizer que o espaço das tradições e de turismo religioso era anteriormente arreigado e intenso.

Nesta cidade havia muitos camelos de aluguer para transportar os turistas estrangeiros durante seis dias através do deserto, extremamente seco, onde não germinava nem erva, nem fruto de nenhuma qualidade, excepto palmeiras. Por aí seguiram os peregrinos até chegarem a Gaza, cidade bíblica de Sansão, riquíssima em todos os produtos. Quanto ao monte Sinai, às memórias de Moisés, a toda uma mitologia enraizada na cultura judeo-cristã, quanto aos muitos mosteiros que lá atraíram milhares de peregrinos desde o séc. IV: nem uma palavra. É mais uma fatia do espaço comum, que é separada do conjunto.

Mas voltemos ao percurso: de Gaza, por Emaús, chegam a Jerusalém, que desde 639, havia cerca de dois séculos e meio, estava sob o domínio árabe. A primeira surpresa é a existência de um hospital, onde são recebidos todos os peregrinos «lingua loquentes Romana» ${ }^{(20)}$, que falam língua romance, não já latim, e que tem anexa uma excelente biblioteca, por zelo e iniciativa do imperador Carlos Magno, com doze mansões, campos e vinhas e jardim no vale de Josafat. Esta informação é confirmada pela Vita Karoli de Eginardo ${ }^{(21)}$. O comércio está bem organizado. Cada negociante paga, para vender no mercado, uma taxa anual.

Os peregrinos parecem observar com interesse o bom funcionamento das instituições de Jerusalém sob domínio árabe. Feitas estas observações, são

\footnotetext{
(19) Ibidem.

(20) Idem, PL 121: 572A.

(21) Via Caroli Magni 16 e 27, PL 97: 40 e 51.
} 
descritos os monumentos e lugares de interesse: o Calvário, o Santo Sepulcro, cuja descrição é remetida para Beda o Venerável: uma nota que basta para caracterizar o autor do Itinerarium. Por esta descrição deduz-se que o cristianismo está em plena pujança, sem nenhuma restrição de culto. É patriarca de toda a Cristandade da Terra Santa um monge de um mosteiro que fica a cerca de $20 \mathrm{Km}$ de Jerusalém.

Entre os monumentos é referenciada a synagoga Saracenorum, ou seja, uma mesquita junto do lugar onde fora o templo de Salomão. Os três cultos existem em pacífica convivência, com grande proeminência do Cristianismo. Enfim, são visitados todos os lugares de interesse, com toda a liberdade. Jerusalém está organizada para explorar o turismo religioso. Cada recanto conta a sua história ou a sua lenda. Há roteiros bem mais fornecidos de relíquias e de factos piedosos. Neste só nos foi mostrado um espinho da coroa da flagelação e a deliciosa piscina em que Lázaro tomou banho quando regressou dos mortos. A credulidade não tem limites.

De Jerusalém vai-se visitar Belém, um pouco a sul, e as margens do Jordão: são muitos os mosteiros e os monges. Uma nota dissonante é que a dois quilómetros da cidade de Jerusalém, do lado ocidental, fica a igreja de Santa Mamila ain qua sunt multa corpora martyrum, qui a Saracenis interfecti ab ipsa sunt ibi diligenter conditi” ${ }^{(22)}$. Não se pode esconder que houve mortos e mártires e há uma comunidade que exibe os seus nas barbas dos dominadores.

De repente diz o roteiro que os três peregrinos «intraverunt in mare» ${ }^{(23)}$, isto é, dirigiram-se para o mar e chegaram a Roma. Viagem por mar, é certo. Mas como? Por onde? Seria interessante que tivéssemos a descrição do regresso. Mas não. O que temos é uma descrição dos monumentos da Cidade

\footnotetext{
(22) Bernardi itinerarium, PL 121: 573.

(23) Idem, PL 121: 574.
} 
Eterna. E de súbito, com vontade de concluir a obra rapidamente, somos levados para Mont-Saint-Michel «qui porrigitur in mare per duas leucas" ${ }^{(24)}$.

Em conclusão: salta à vista que há um clima de tensão controlada em todo este roteiro. A presença cristã é fortíssima desde que pusemos o pé no Egipto. Mas há restrições de movimentos relativamente aos itinerários mais antigos. A viagem na Terra Santa foi circunscrita a Jerusalém e arredores, e a Belém com um salto ao Jordão. Nem Nazaré, nem o lago de Tiberíades, nem o Tabor. Todo o séc. IX foi marcado por grande actividade militar muçulmana no Ocidente. Ocupação da Sićlia, ocupação do Sul de Itália. Em 846 piratas muçulmanos saqueiam S. Pedro em Roma. O ambiente era de grande desconfiança e de extrema insegurança. O Mediterrâneo fecha-se cada vez mais.

(24) Iibidem. 